DOI: $10.5007 / 2175-7941.2012 v 29$ nesp1p420

\title{
ESTUDOS SOBRE A AÇÃO MEDIADA NO ENSINO DE FÍSICA EM AMBIENTE VIRTUAL ${ }^{+*}$
}

Pedro Alexandre Lopes de Souza

Laboratório de Pesquisas em Educação Química e Inclusão - LPEQI, IQ Universidade Federal de Goiás

Geiziane Silva Oliveira

Laboratório de Pesquisas em Educação Química e Inclusão - LPEQI

UnUCET - Universidade Estadual de Goiás

Claudio R. Machado Benite

Laboratório de Pesquisas em Educação Química e Inclusão - LPEQI

UnUCET - Universidade Estadual de Goiás

Anna M. Canavarro Benite

Laboratório de Pesquisas em Educação Química e Inclusão - LPEQI, IQ

Universidade Federal de Goiás

Goiânia - GO

\section{Resumo}

A nova geração da internet tem notoriamente se apresentado como fator decisivo nas tomadas de rumo da sociedade por meio da utilização de diversas ferramentas interativas, o que possibilita (re)construir o conhecimento. Nela, tudo é cada vez mais dinâmico e a interação é cada vez mais natural, tanto em termos visuais, quanto em sua linguagem de programação. Assim, as Tecnologias de Informação e Comunicação (TIC's), em especial a Web 2.0, têm-se incorporado a processos educativos. Este artigo versa so-

\footnotetext{
Studies about the mediated action on Physics Education in a virtual environment

* Recebido: janeiro de 2012. Aceito: julho de 2012.

'Esta é uma versão ampliada e revisada de texto apresentado pelos autores no VII Encontro Nacional de Pesquisa em Educação em Ciências, 2011.
} 
bre a representação de modelos científicos utilizando aplicativos computacionais. Assim, planejamos e desenvolvemos um produto tecnológico (portal interativo - Ealuno), utilizando os recursos da Web 2.0 tendo em vistas sua utilização como ferramenta da ação mediada de ensino e aprendizagem de fisica. Discorremos sobre como essa forma de apresentação se insere na aula de ciências/fisica e descrevemos suas funcionalidades. Esta é uma investigação que se caracteriza como uma pesquisa participante. Neste caso, assumimos duas posições, pois representamos os professores de ciências que ensinam para a sociedade tecnológica e os membros dessa sociedade tecnológica, isto é, representa-se a sala de aula de física condicionada por novas formas de comunicação a partir de posições definidas e legitimadas nessa estrutura social. Nossos resultados demonstram que a configuração do Ealuno permite diferentes meios de registro e representação da realidade que lhe confere utilidade na ação mediada, e esta utilidade está no poder de interatividade e no acesso a ambientes virtuais, oferecendo aos usuários interação e motivação, para o processo de ensino-aprendizagem de física.

Palavras-chave: Ambiente Virtual de Aprendizagem. Ensino de Física. Plataforma Web 2.0.

\begin{abstract}
The new generation of Internet has notoriously been a decisive factor in direction-making of society through using interactive tools, which enables (re)build the knowledge. Here, everything becomes more dynamic and the interaction is increasingly more natural, both in visual terms and programming language. Thus, the Information and Communication Technologies, especially the Web 2.0, have been incorporated into educational processes. This article deals with the representation of scientific models using computer applications. Thus, it was planned and developed a technology product (interactive portal-Ealuno), using the resources of the Web 2.0, considering its use as an action tool for Physics teaching and learning. We discuss about how this way of presentation is inserted in Science/Physics class and described its
\end{abstract}




\begin{abstract}
functions. This is an investigation characterized as a participant research. In this case, we assume two positions, since we represent the Science teachers who teach for a technological society and the members of this technological society, that is, we represent the Physics classroom conditioned by new ways of communication from defined and legitimized positions in this social structure. Our results indicate that the student configuration allows different ways of record and representation of the reality that promotes to it a utility in the mediated action, being this utility in the interactivity power and in the access to virtual environments, permitting to provide to users interaction and motivation for the Physics teaching and learning process .
\end{abstract}

Keywords: Virtual Learning Environment. Physics Teaching. Web 2.0 Platform.

\title{
I. Introdução
}

As profundas transformações sociais e econômicas sofridas no século XX produziram desdobramentos que trilharam o caminho ascendente do conhecimento. Essa sociedade, por consequência, passou a ser intitulada Sociedade do Conhecimento (LÉVY, 2000). Contudo, o que acompanhamos agora, no século XXI, é a formação de outra sociedade, a Sociedade da Informação, ou ainda mais recentemente, Sociedade da Aprendizagem (POZO, 2002). Como ressalta Bartolomé (2005), enquanto em milhares de anos o conhecimento acumulado pela sociedade cresceu em ritmo lento, hoje acompanhamos uma "explosão" de informações, porém, extremamente voláteis e muitas delas de fontes pouco confiáveis. Além disso, o excesso de informação não é garantia necessária para um processo de produção do conhecimento.

Segundo Lindley (2000), o termo sociedade da informação se refere à

enorme proliferação da informação, estimulada pelo aproveitamento da microeletrônica e pelas primeiras manifestações do seu potencial impactante social e econômico. Em contrapartida, o conceito de sociedade da aprendizagem transporta em si a concepção embrionária do modo de vida moderno (LINDLEY, 2000, p. 36).

As diversas teorias sobre a criação de uma sociedade da informação indicam uma mudança radical em todos os setores, principalmente, na educação. Nesse 
contexto, as tecnologias de informação e comunicação (TIC'S) operam como forças propulsoras que modelam as relações sociais, econômicas e políticas (GARCIA, 2005). Contudo, concomitante à educação como instrumento estratégico da reprodução social, "as tecnologias permitem dar um grande salto nas formas, organização e conteúdo da educação" (DOWBOR, 1996, p. 20).

As TIC's no contexto social modificam a comunicação, o aprendizado e o conhecimento; estes, os quais possuíam características lineares e sequenciais, além de serem marcados pela oralidade e pela escrita manual são substituídos por ambientes amparados pelas TIC's. Por sua vez, a construção do conhecimento ocorre pelas diversas linguagens simultâneas, apontadas por Bartolomé (1999) como sistemas multimídicos. Se, por um lado, as formas de se produzir o conhecimento estão passando por profundas transformações, também estão se transformando nossas percepções, nossos valores e nossa cultura, fato que repercute diretamente na dinâmica de nossas salas de aula.

No que diz respeito à mediação, é necessário reconhecer que tal conceito constitui a discussão central da obra de Vygotski (2001). Em um sentido amplo, a mediação pode ser entendida como toda intervenção de um terceiro elemento que possibilita a interação entre os termos de uma relação. Importa considerar que existe tensão irredutível entre mediadores e ferramentas culturais (em nosso caso, a segunda geração da internet), e essa tensão pode ser determinante da ação mediada (BENITE; BENITE, 2008). Ora, se vivemos neste cybermundo repleto de informações que nos inundam, importa compreender como as TIC's se inserem na ação mediada.

\section{Sobre a segunda geração da internet}

Se para muitos acessar a internet é uma novidade e mesmo um grande desafio, para outros muitos, ela já se fez ultrapassada e com recursos restritos, precisando, assim, ser "repaginada". Esse novo pacote de ferramentas e usabilidades online foi denominado de Web 2.0 por Tim O’Reilly (2005). Para ele,

a Web 2.0 é a mudança para uma internet como plataforma, e um entendimento das regras para obter sucesso nesta nova plataforma. Entre outras, a regra mais importante é desenvolver aplicativos que aproveitem os efeitos de rede para se tornarem melhores quanto mais são usados pelas pessoas, aproveitando a inteligência coletiva (O'REILLY, 2005, p. 45).

Desse modo, a Web 2.0 (termo que faz uma analogia com o tipo de notação em informática indicando a versão de um software) é a segunda geração de 
serviços online e se caracteriza por potencializar as formas de publicação, compartilhamento e organização de informações, além de ampliar os espaços para a interação entre os participantes do processo.

Entre as ferramentas da $\mathrm{Web} 2.0$, baseadas em redes sociais, podem ser citados os sites de compartilhamento de vídeos (YouTube), as redes de relacionamento (Orkut), enciclopédia colaborativa (Wikipedia), editores de páginas web colaborativos (PBwiki) e simuladores de vida real (Second Life) (BEHAR et al., 2009, p. 310).

Para Alexander (2006), as principais características da Web 2.0 são:

Interfaces ricas e fáceis de usar; (...) ii) O sucesso da ferramenta depende do número de utilizadores, pois deles depende a melhoria do sistema; (...) iii) Gratuidade na maioria dos sistemas disponibilizados; (...) iv) Maior facilidade de armazenamento de dados e criação de páginas online; (...) v) Vários utilizadores podem acessar a mesma página e editar as informações; (...) vi) As informações mudam quase que instantaneamente; (...) vii) Os sites/softwares estão associados a outros aplicativos tornando-os mais ricos e produtivos quando os mesmos estão trabalhando na forma de plataforma (união de vários aplicativos); (...) viii) Os softwares funcionam basicamente online ou podem utilizar sistemas offline com opção para exportar informações de forma rápida e fácil para a web; (...) ix) Os sistemas param de ter versões e passam a ser atualizados e corrigidos a todo instante, trazendo grandes beneficios para os utilizadores (ALEXANDER, 2006, p. 32-44).

Os recursos da Web 2.0 oferecem ao aprendiz tecnologia que lhe permite, efetivamente, usar a língua em experiências diversificadas de comunicação. A Fig. 1 sintetiza a evolução da $W e b$ e a chegada da Web 2.0 em uma linha de tempo ilustrada.

A Web 2.0 é uma importante ferramenta para o ensino e a aprendizagem, pois exige que em sua utilização seja priorizada a qualidade. Quando usada de forma efetiva, desempenha um papel importante para o desenvolvimento do aluno, promovendo a iniciativa pessoal e de grupo, a solidariedade, o respeito mútuo e a formação de atitudes sociais, sendo um poderoso elemento de motivação no ambiente de aprendizagem.

Assumidos esses pressupostos, esta investigação versa sobre a representação de modelos científicos utilizando aplicativos computacionais. Assim, planejamos e desenvolvemos um produto tecnológico (portal interativo) utilizando os recursos da Web 2.0 tendo em vista sua utilização como ferramenta da ação mediada de ensino e aprendizagem de física. Discorremos sobre como essa forma de 
apresentação se insere na aula de ciências/física e, finalmente, descrevemos suas funcionalidades.

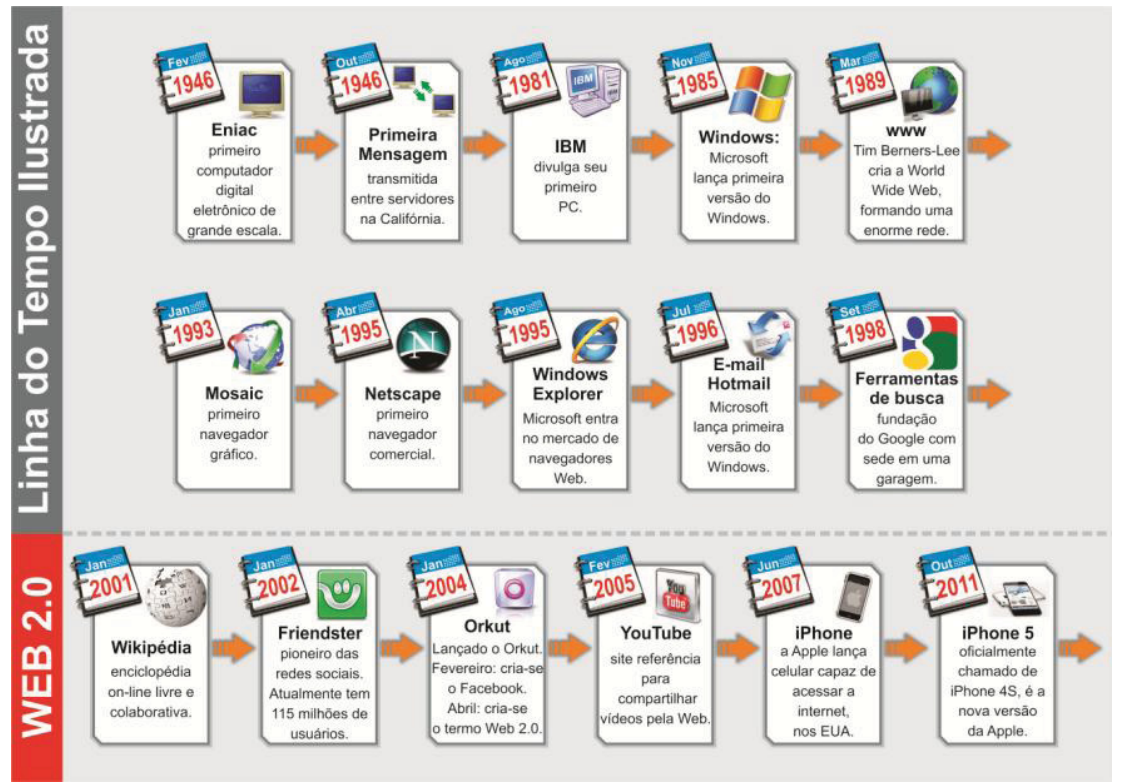

Fig. 1 -Evolução da Web.

\section{A opção metodológica}

Este trabalho apresenta elementos de uma pesquisa participante, isto é, trata-se de uma investigação social por meio da qual se busca a participação da comunidade na análise de sua própria realidade, com o objetivo de promover ações coletivas para o beneficio da comunidade escolar. Trata-se, portanto, de uma atividade educativa de investigação e ação social (BRANDÃO, 1984).

Cabe esclarecer que a participação em uma pesquisa, segundo Demo (2004), está para além de pertencer a essa comunidade: ela deve dar voz à mesma. Nesse caso, assumimos as duas posições, pois representamos os professores de ciências que ensinam para a sociedade tecnológica e os membros dessa sociedade, isto é, representa-se a sala de aula de ciências condicionada por novas formas de comunicação a partir de posições definidas e legitimadas nessa estrutura social. Ainda, conforme Demo (2004), a pesquisa participante é uma alternativa de se aliar simultaneamente o conhecimento e a participação, buscando dar autonomia e 
capacidade de emancipação cidadã aos envolvidos no processo, especificamente no trato com o situar-se dentro de uma sociedade tecnológica.

Dessa forma, os autores (dois professores formadores de duas instituições públicas de ensino superior do estado de Goiás - PF1 e PF2, um professor de física em formação continuada - PG1 e uma professora de química em formação inicialPFQ) planejaram e desenvolveram, durante o ano de 2010, um portal interativo nomeado Ealuno (www.ealuno.net), com três características básicas: pode ser acessado por meio do computador e do celular (smartphone), preferencialmente pela internet; visa disponibilizar atividades pequenas, ou seja, que podem ser utilizadas no tempo de uma ou duas aulas; e focaliza um objetivo de aprendizagem único - o ensino de ciências/física.

Importa esclarecer o que é o Ealuno: trata-se de um portal do Laboratório de Pesquisas em Educação Química e Inclusão - LPEQI (www.quimica.ufg.br), que surgiu com o objetivo de disponibilizar um canal para que professores, licenciandos e alunos de ciências (Química, Física, Biologia e Matemática) possam obter auxílio para suas aulas; possibilitar a discussão do ensino por meio de participação de professores de todo o país. Assim, o portal é um espaço dedicado aos níveis fundamental, médio e superior, e busca estender o espaço de discussão das salas de aula, ou seja, ampliar o tempo da prática pedagógica. No portal, disponibilizamos materiais produzidos a partir de diferentes tecnologias e linguagens interativas como apoio ao trabalho desenvolvido nas salas de aula de ciências/física.

O Ealuno foi apresentado pelo professor (PG1) a uma turma de vinte dois alunos (A) do segundo ano do Ensino Médio de uma escola privada de Goiânia, convidada a participar da investigação de forma volitiva.

Durante o segundo semestre de 2011, a partir da discussão conceitual sobre o tópico ondas, iniciado em sala de aula, na disciplina de física (presencial), os sujeitos da investigação foram convidados a desenvolver atividade (durante o período compreendido entre 01/11/2011 e 18/11/2011) sobre a temática no Ealuno (em ambiente virtual).

Cabe esclarecer que o instrumento de coleta de dados utilizado foi o próprio portal, uma vez que ele nos fornece os registros de permanência dos sujeitos, tal como explicitaremos no próximo tópico.

Apoiamo-nos em Postman (1994) para afirmar que "nosso instrumento ideológico mais poderoso é a tecnologia da própria língua" (p. 129). É a língua (escrita, falada ou viso-espacial) que nos instrui, que forma nossos conceitos a respeito das coisas e em relação a como estamos com os outros. Por isso, nesta investigação, utilizamos como objeto de estudo o discurso escrito (a palavra escrita) produzido pelos sujeitos da investigação a partir da técnica de análise da con- 
versação (MARCUSCHI, 2007) aproveitando elementos de análise da prática discursiva em sala de aula (SMOLKA, 1991).

A técnica de análise da conversação surgiu como uma das expressões empíricas da etnometodologia. Sua divulgação está ligada à publicação, na década de 1960, da Obra Studies in Ethomethodology, de Harold Garfinkel (1967). Segundo o autor, essa linha de estudo

aborda as atividades práticas, as circunstâncias práticas e as situações de raciocínio sociológico prático, como temas de estudo empírico. Concedendo às atividades corriqueiras da vida cotidiana a mesma atenção que habitualmente se empresta aos acontecimentos extraordinários, tentamos compreendê-los como fenômenos de direito pleno (GARFINKEL, 1967, p. 1).

Assim, voltaremos nossa atenção para a apreensão de como os sujeitos da pesquisa "criam, reúnem, produzem e reproduzem as estruturas práticas para as quais se orientam", isto é, a ação mediada (HERITAGE, 1999, p. 333).

\section{Caracterizando o Portal Ealuno: uma ferramenta para a ação me- diada}

\section{IV.1 O planejamento}

O Planejamento do Portal Ealuno consistiu das seguintes etapas: i) escoIha de uma linguagem, disponibilizando elementos gráficos e códigos-fonte, sendo os últimos arquitetados e desenvolvidos no intuito de proporcionar maior funcionalidade, sem é claro, perder dinamicidade. Assim, temos como Regime de Programação: PHP, JavaScript, HTML, CSS, FLASH; ii) diagramação do layout; iii) a utilização de softwares específicos para o desenvolvimento e para a edição do corpo do portal e sistematização de materiais produzidos.

\section{IV.2 O design em ação}

Segundo Kenski (2007), a imagem, o som e o movimento dão maior realismo ao que está sendo ensinado acrescentando informações que possibilitam maior compreensão e verticalização dos conteúdos abordados, provocando, assim, uma modificação no comportamento tanto de alunos como de professores. Cabe salientar que a escola não deve ser apenas consumidora de tecnologia, mas também produtora dessa tecnologia. "Usamos muitos tipos de tecnologias para aprender e saber mais, e precisamos da educação para aprender e saber mais sobre as tecnologias" (KENSKI, 2007, p. 44). 
Baseados nesses pressupostos, confeccionamos o Ealuno com a seguinte estruturação midiática: parte externa (visualização e apresentação de algumas ferramentas), parte operacional (gerenciamento) e parte interna (relatórios de visitação).

O layout (parte externa) foi executado a partir de considerarmos que

A ação pedagógica poderá tomar uma nova forma, quando imersa numa cultura imagética, que fabrica o produto do olhar por meio do digital. $O$ digital que alarga o acesso; apresenta novos dispositivos; desmonta e reconstrói antigas relações entre imagem e ação. Novas associações se construirão entre produto imagético (vídeo digital) e construção do olhar (neuroimagem) (MARTINS; SANTANA, 2009, p. 9).

A página inicial do Portal Ealuno apresenta menus de fácil acesso a assuntos/conteúdos voltados ao ensino de ciências/física que permitem ampliar o tempo de discussão em sala de aula e que são atualizados automaticamente conforme a última postagem abordada, existindo uma rotatividade, através da qual os assuntos mais recentes ficam disponíveis na homepage, conforme Fig. 2.

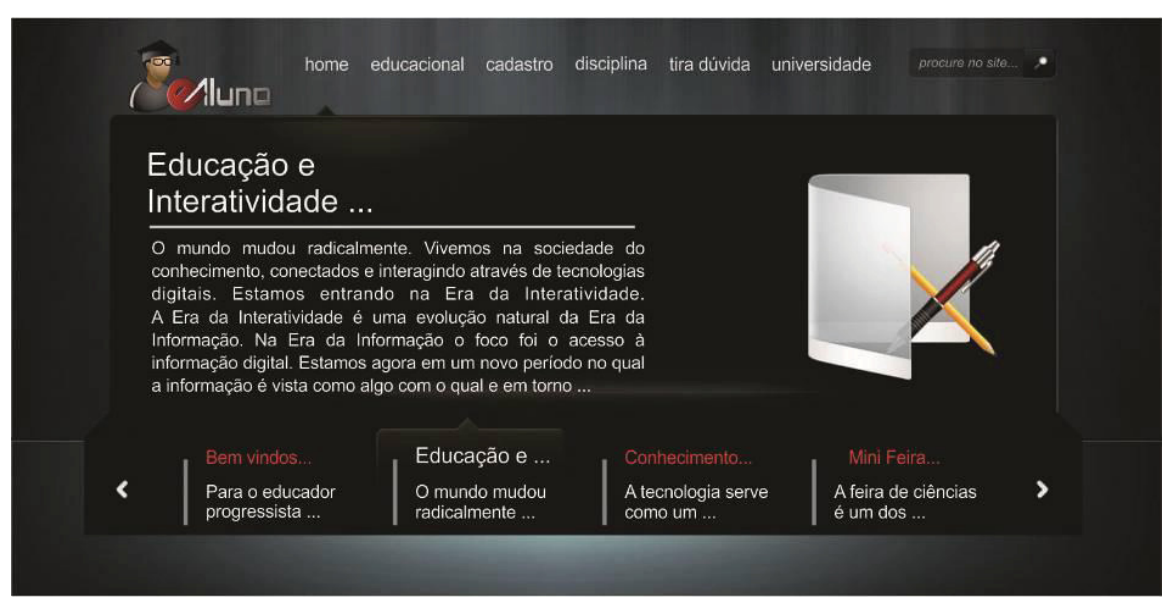

Fig. 2 - Homepage do Portal Ealuno.

Dentro de cada postagem levantada para discussão o usuário poderá visualizar o conteúdo na parte principal, podendo interagir através de comentários e/ou perguntas sobre o assunto. Assim, é importante que o mesmo faça um breve registro para que seja montado um perfil dentro do portal. A partir daí, o estudante poderá postar seus comentários que serão identificados no portal por nome e um 
$\operatorname{avatar}^{2}$ (Fig. 3).

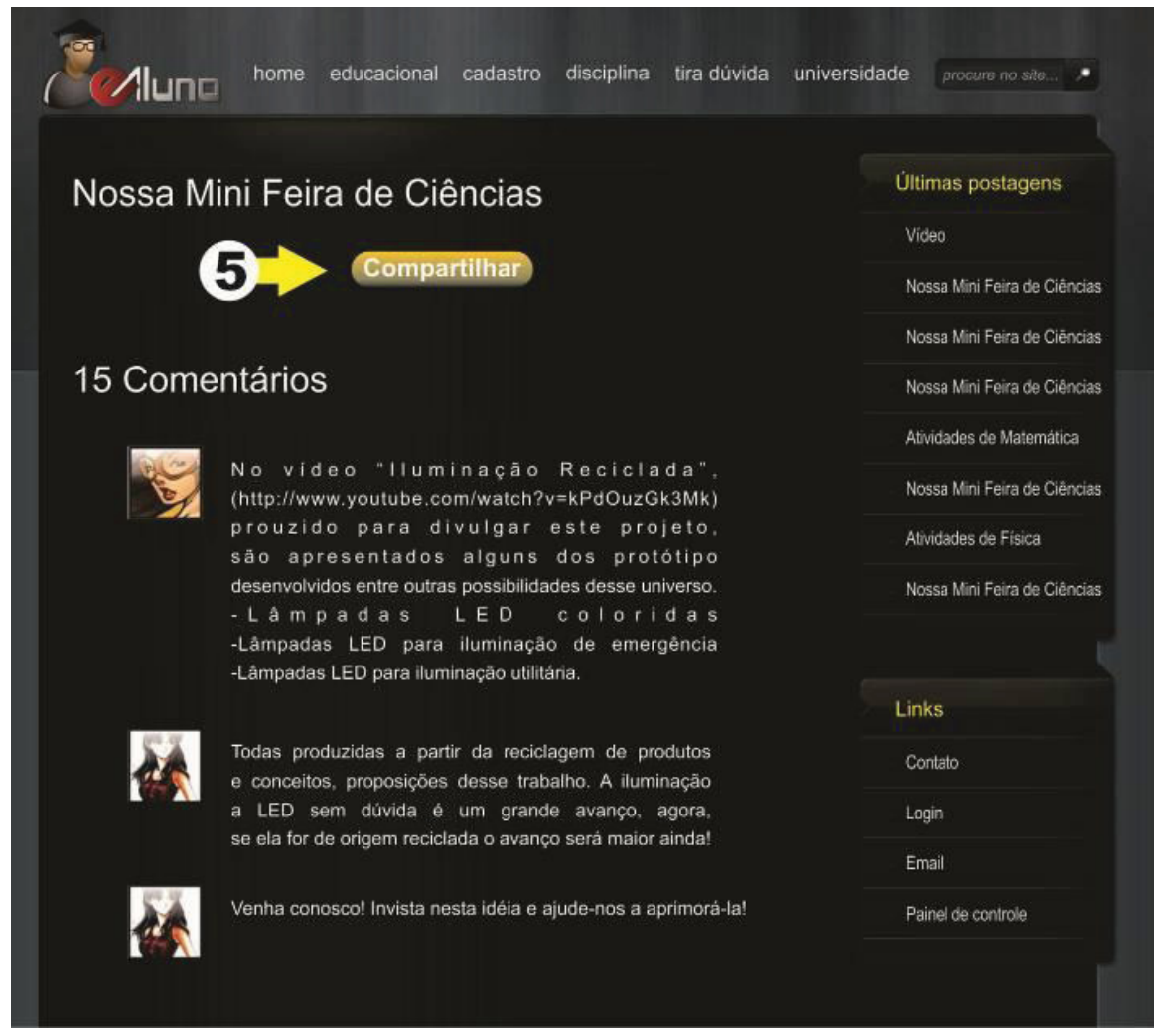

Fig. 3 - Abordagem do assunto e comentários.

Caso o estudante se interesse, ele pode acessar as postagens incorporadas por disciplinas, onde encontrará tópicos relacionados a essa área do conhecimento (veja Fig. 4).

Nela podemos identificar:

- Postagens (seta número 1): pode-se adicionar qualquer tipo de mídia, seja ela uma reportagem, um vídeo, uma animação, uma apresentação de Power

${ }^{2}$ Avatar é uma representação em forma de imagem ou mesmo em 3D que personifica o usuário na rede quando este redige comentários. Para obter um avatar, é necessário antes fazer um cadastro utilizando o e-mail, que corresponderá ao mesmo do login no portal. 
Point ou mesmo todas ao mesmo tempo interagindo.

- Discussão on-line (seta de número 2): neste recurso, o aluno através do próprio site poderá ter acesso ao Live Messenger (conhecido entre os internautas por Msn) sem que este seja instalado em seu computador, o que lhe permite ter uma conversação on-line com o professor da disciplina que pode inclusive abrir a conversa a todos os usuários que estiverem on-line.

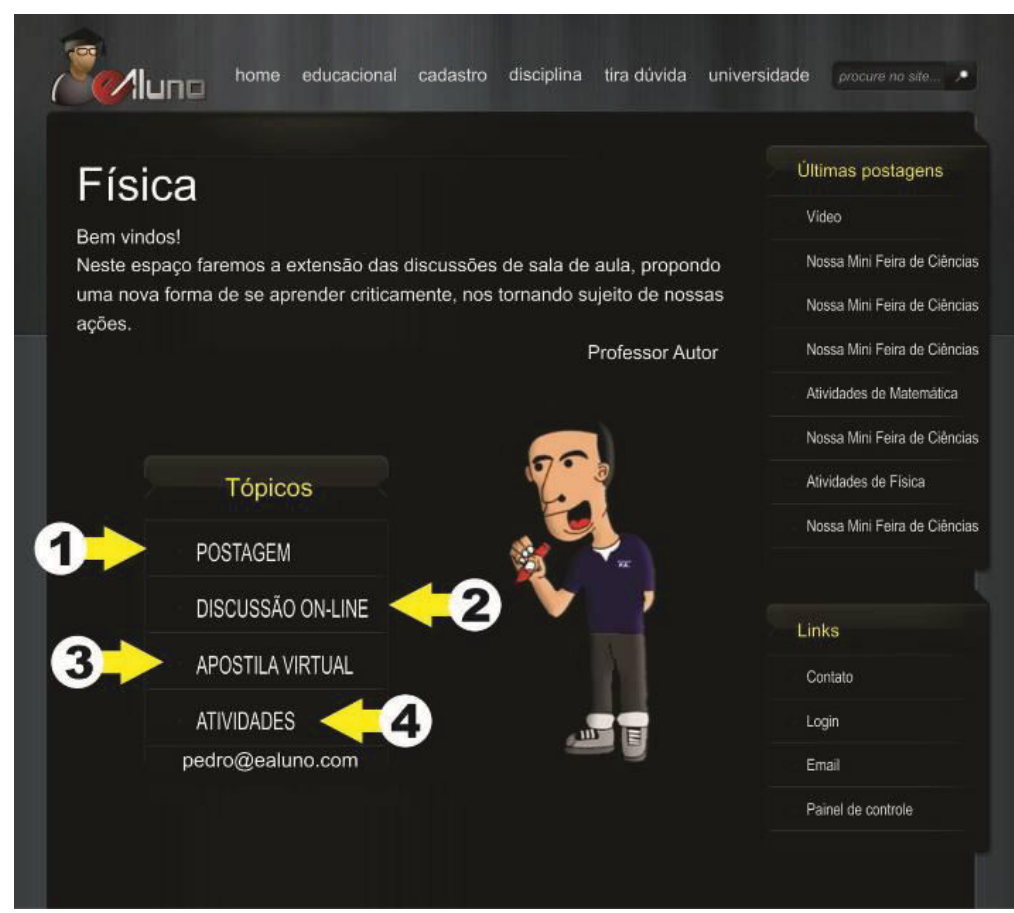

Fig. 4 - Página da disciplina de Física.

- Apostila Virtual (seta de número 3): ambiente que simula uma apostila, onde podem ser anexados conteúdos das disciplinas, inclusive, fornecidos pelos próprios alunos através de envio prévio de material. A apostila pode ser compartilhada ou mesmo impressa.

- Atividades (seta de número 4): aqui podem ser propostas em um ambiente diferenciado atividades para que o estudante possa desenvolver e colocar em prática o que ele está discutindo, pois, segundo D'Ambrósio (1996) "não há dicotomia, entre o saber e o fazer, não há priorização entre um e o outro", ou seja, o portal se preocupa em apresentar ao sujeito opções para fazê-lo.

Vale ressaltar que todas as postagens, as perguntas e os comentários pos- 
suem um botão de compartilhamento com funcionalidade $W e b 2.0$, por meio do qual o aluno poderá compartilhar (seta de número 5, na Fig. 3) as postagens/conteúdo em mais de trezentas e vinte redes sociais diferentes (Orkut, Twitter e Facebook).

A parte operacional do portal é gerenciada através de uma plataforma semântica para publicação denominada WordPress, um software livre e gratuito que possibilita o desenvolvimento de funcionalidades e administração. Neste ambiente, inicialmente se valida o usuário e a senha do acesso, destacando que a tela é a mesma tanto para usuários quanto para outros perfis, tais como o administrador, criando um nivelamento entre os "editores".

Pode-se visualizar, após autenticação de usuário e senha na plataforma WordPress, as funcionalidades da mesma, como adicionar postagens/comentários, gerenciar inserção de mídias e controlar os usuários cadastrados, dependendo de seu tipo de perfil/função (assinante, colaborador, autor, editor e administrador).

A parte interna do portal disponibiliza detalhes sobre a visitação (diferentes tipos de relatórios de visitação, Fig. 6), permitindo mapear como os visitantes navegam pelo mesmo, fornecendo registros de permanência e localizando o tráfego de informações, recurso que permite com que o portal seja utilizado também como instrumento de coleta de dados em investigações futuras sobre sua validade na ação mediada.

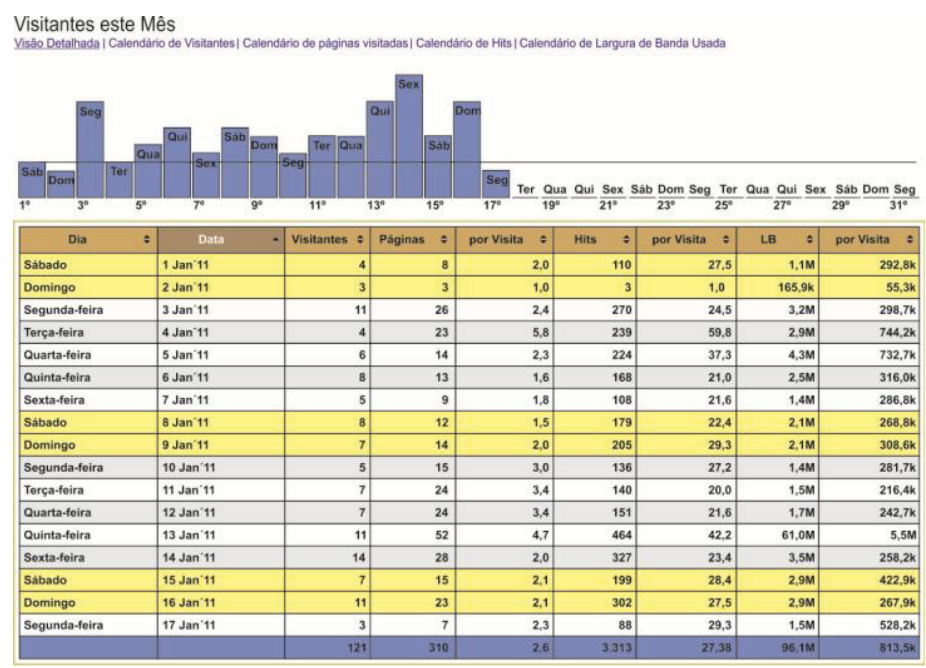

Fig. 6-Relatório de visitantes do mês. 
É importante salientar que realizamos, no primeiro semestre do ano de 2011, uma atividade com a finalidade de adequar o desenvolvimento e estruturação do portal. Portanto, todas as fotos do sistema correspondem a momentos de sua utilização em sala de aula de física.

\section{Resultados e discussão}

\section{V.1 Sobre a atividade desenvolvida}

Apoiamo-nos em Machado (2009) para afirmar que a realidade física é complexa e seu conhecimento está condicionado a idealizações e aproximações, porém, no ensino de física, nós, professores, tratamos dos resultados finais desse processo complexo. Dessa forma, entendemos que a física é um processo de representação do mundo que sempre está se (re)construindo e, assim, o conhecimento físico é povoado por entidades de representação. "Por exemplo, a lei da gravitação universal de Newton é uma forma de representar, através de um modelo matemático, a interação entre corpos celestes" (VEIT; TEODORO, 2002, p. 88).

A linguagem física tem seu poder na sua capacidade de representação e de descrição do processo natural, ou seja, utilizando equações é possível reproduzir, com devidas aproximações, em papel (quando não se tinha o computador) o que se passa no céu, como no caso de Newton.

Quando se trata do ensino e aprendizagem de Física, lidamos com constructos teóricos - os modelos -, que são as representações simplificadas de um sistema. Portanto, cabe considerar que aprender é um processo de construção social intimamente relacionado com as ferramentas das interações sociais, e a ferramenta dessa interação é o computador, que pode facilitar estudos exploratórios e estender o tempo de sala de aula. Neste contexto, apresentamos o recorte de uma das atividades desenvolvidas no Ealuno: um objeto virtual de aprendizagem (OVA) (Fig. 7).

Sob o título "Decifrando a cozinha cientificamente" (DLPEQI, 2011), a atividade é uma simulação dos princípios físicos envolvidos com o funcionamento do forno micro-ondas, tecnologia presente no cotidiano dos alunos, tal como apresentado na Fig. 8. O OVA simula características do comportamento ondulatório das ondas eletromagnéticas, em particular, as micro-ondas.

A simulação apresentada modela uma realidade física, ou seja, é um constructo teórico da interpretação da realidade sob a óptica mais especificamente da física. Nesse aspecto, vale considerar que o Portal Ealuno se instaura como ferramenta da ação mediada, pois, possui instrumentos que possibilitam representar e 
mesmo transformar a natureza da comunicação das ciências, simulando a realidade.

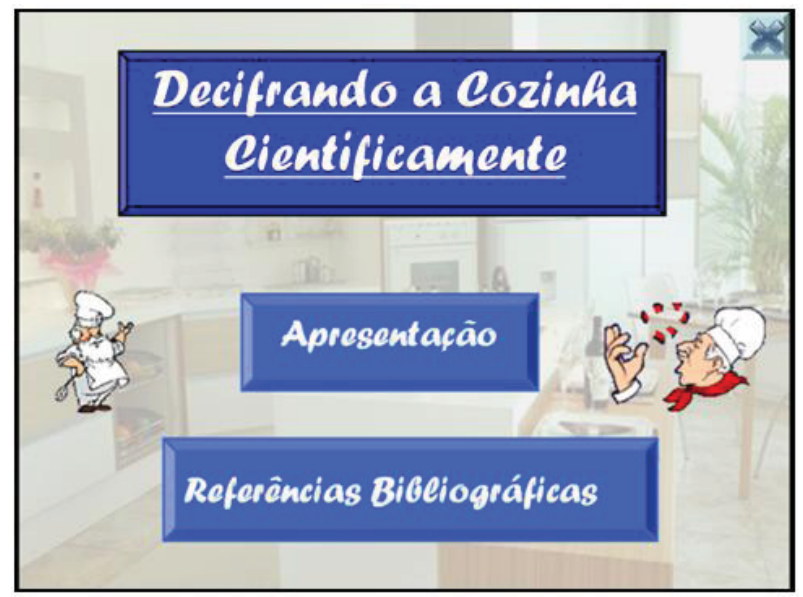

Fig. 7- Tela de apresentação do OVA.

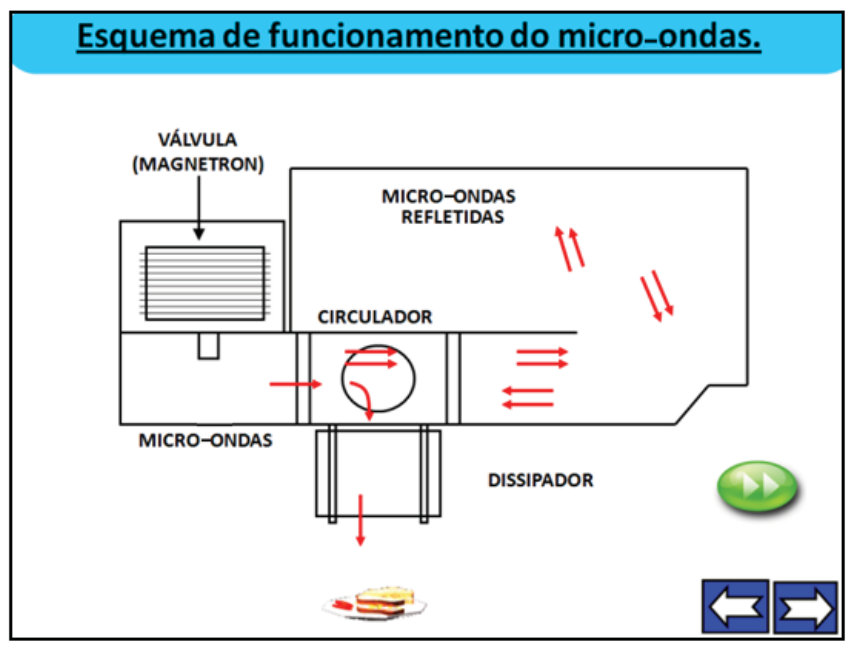

Fig. 8 - Simulação do funcionamento do aparelho de micro-ondas (baseado em BARBOZA et al., 2001). 
Corroborando com resultados anteriores, dotamos o Portal Ealuno de recursos de modelagem computacional, os quais

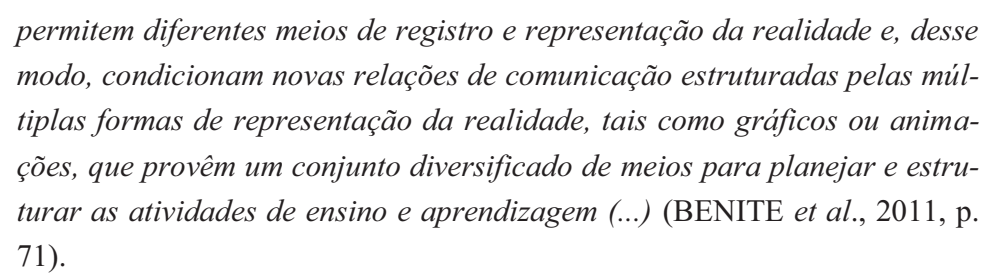

As representações da realidade consistem em uma espécie de filtro dessa mesma realidade, por meio da qual o homem é capaz de vislumbrar o mundo e promover ações. Em computadores, essas representações dão ênfase à tríade linguagem, imagem e ação, os quais consideramos elementos indispensáveis para a apropriação dos conceitos científicos.

A Fig. 9 apresenta a simulação em termos de sua descrição triádica: linguagem escrita sobre a simulação em questão, diagramação baseada em imagens estáticas (caso do esquema do aparelho micro-ondas em corte lateral - lado inferior esquerdo), botões que simulam o comportamento do campo, estes que estão "hiperlincados" ao movimento das moléculas sob a ação do campo, simulando, assim, o seu alinhamento e realinhamento, associando dinamicidade ao produto tecnológico em questão.

As representações evocadas a partir da integração entre imagem, linguagem e ação visam permitir ao usuário do portal maior movimentação em relação às variáveis que enunciam o conceito. Desse modo, o Portal Ealuno nos parece poder atuar como uma ferramenta cognitiva para auxiliar a internalização de conhecimento simbólico, preferencialmente em contexto de atividades de grupo e de classe, em que a discussão, a conjectura e o teste de ideias são atividades dominantes em oposição ao ensino conteudista e pragmático.

O design dessa ferramenta computacional visou permitir ao usuário fazer e refazer representações, explorando-as sobre diferentes perspectivas. Assim, parece-nos possibilitar a familiarização com essas representações, criando uma intimidade entre aprendiz e representação, "intimidade essa que muito dificilmente resulta da simples observação ocasional de equações e representações feitas pelo professor ou apresentadas nos livros" (VEIT; TEODORO, 2002. p. 90). 


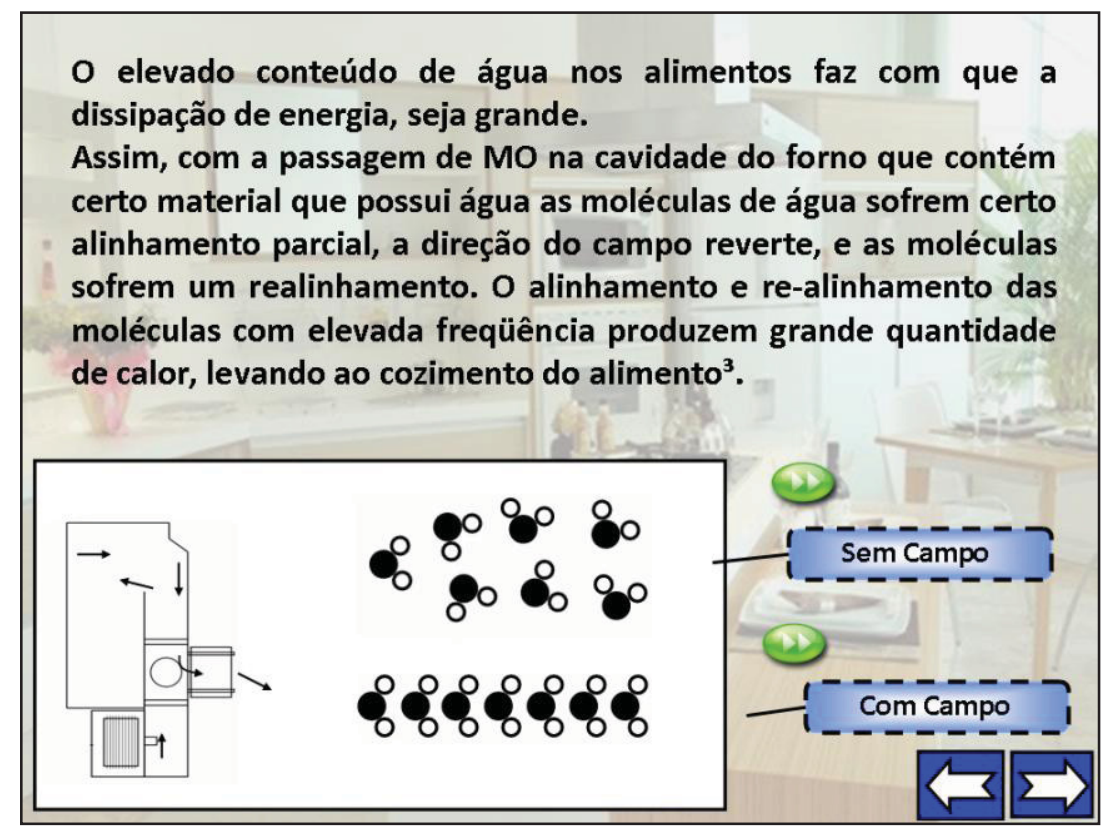

Fig. 9 - Simulação da atuação das moléculas de água no aquecimento por micro-ondas (baseado em BARBOZA et al., 2001).

Os sujeitos da investigação foram convidados a postar comentários acerca da atividade ou mesmo discutir sobre comentários já feitos por outros usuários, a fim de estender o tempo de discussão da sala de aula para a internet, isto é, o não espaço físico de uma escola. Importa ressaltar que permitir ao usuário criar familiaridade com as representações por meio da manipulação destas não é sinônimo de aprendizagem, pois ninguém pode aprender sem conhecimento sobre essas representações.

\section{V.2 Estudos sobre a ação mediada}

Essa atividade produziu 281 turnos de discurso e passamos a apresentar a análise de um extrato de diálogo produzido pelos sujeitos desta investigação intitulado "Sobre a natureza da radiação eletromagnética". 
Extrato 1: Sobre a natureza da radiação eletromagnética.

\begin{tabular}{|c|c|}
\hline Autor: & Comentário: \\
\hline m & 1. Enviado em 02/11/2011 as 8:35 pm \\
\hline \multirow{5}{*}{$\begin{array}{l}\text { PG1 } \\
\text { ealuno.net } \\
\text { PG1@hotmail.com }\end{array}$} & Pessoal, o fórum está aberto! Lembrem-se estamos aqui \\
\hline & para dar continuidade à discussão sobre ondas eletromagné- \\
\hline & ticas que começamos lá em sala de aula. \\
\hline & $\begin{array}{l}\text { Deixem seus comentários, nossa discussão depende única e } \\
\text { exclusivamente de sua participação. }\end{array}$ \\
\hline & Bom estudo a todos... \\
\hline \multirow{4}{*}{$\begin{array}{l}\text { Pal PG1 } \\
\text { ealuno.net } \\
\text { PG1@hotmail.com }\end{array}$} & 2. Enviado em 02/11/2011 as 8:45 pm \\
\hline & Usualmente, em nosso discurso, tratamos indistintamente os \\
\hline & raios eletromagnéticos e a radiação eletromagnética. Porém, \\
\hline & $\begin{array}{l}\text { os raios são os componentes da radiação eletromagnética. } \\
\text { Então, o que é radiação eletromagnética? }\end{array}$ \\
\hline \multirow{4}{*}{$\begin{array}{l}\sqrt{4} \text { A1 } \\
\text { A1@hotmail.com }\end{array}$} & 3. Enviado em 02/11/2011 as 11:05 pm \\
\hline & Para mim é a relação entre um campo elétrico e um campo \\
\hline & $\begin{array}{l}\text { magnético. Essa relação entre os dois transporta energia } \\
\text { pelo espaço. }\end{array}$ \\
\hline & $\begin{array}{l}\text { Pelo que eu entendi toda radiação eletromagnética tem } \\
\text { comportamento de onda, mas nem todas são luz, ou seja, } \\
\text { perceptíveis ao olho humano. Isso depende da frequência. }\end{array}$ \\
\hline \multirow{3}{*}{$\begin{array}{l}\text { A6 } 6 \\
\text { A6@hotmail.com }\end{array}$} & 4. Enviado em 02/11/2011 as $11: 45 \mathrm{pm}$ \\
\hline & Mas, então, se todas as ondas eletromagnéticas transportam \\
\hline & energia, nós, que estamos expostos, recebemos pelo corpo? \\
\hline \multirow{3}{*}{$\begin{array}{l}\infty \\
\text { A2@hotmail.com }\end{array}$} & 5. Enviado em 03/11/2011 as $11: 38 \mathrm{pm}$ \\
\hline & Concordo com o $\mathrm{A} 1$, radiação eletromagnética pelo que eu \\
\hline & $\begin{array}{l}\text { entendi é resultante da interação entre o campo magnético } \\
\text { com o elétrico que viajam na velocidade da luz. Porém A1, } \\
\text { eu entendi que a luz é somente um exemplo de radiação } \\
\text { eletromagnética. Acrescentando um pouco mais à ideia } \\
\text { central, a radiação eletromagnética possui os dois campos } \\
\text { (magnético e elétrico) que se propagam perpendicularmente } \\
\text { e se geram mutuamente, na direção de propagação da ener- } \\
\text { gia, um em relação ao outro transportando a energia em } \\
\text { forma de radiação eletromagnética. Mas, PG1, fiquei em } \\
\text { dúvida no termo se geram mutuamente... }\end{array}$ \\
\hline
\end{tabular}


$\because \div$

A8@hotmail.com

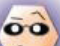

PFQ

PFQ@gmail.com

PFQ

PFQ@gmail.com

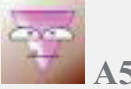

A5@hotmail.com

\section{Enviado em 03/11/2011 as 12:45 pm}

Poderíamos usar a radiação eletromagnética para carregar aparelhos eletrônicos sem necessidade de fios!!!

\section{Enviado em 03/11/2011 as 13:34 pm}

Olá, meninos, gostaria de falar um pouco sobre a relação entre os campos elétrico e magnético. Pode parecer que esses campos associados a uma onda eletromagnética são completamente independentes um do outro, já que as componentes desses campos obedecem a equações independentes. Um campo magnético variável no tempo leva ao surgimento de um campo elétrico. Esse campo elétrico também será variável no tempo e produzirá, por sua vez, um campo magnético variável no tempo e, assim, sucessivamente. Os dois componentes da onda - o campo elétrico e o campo magnético - alimentam-se mutuamente, e isso faz com que a onda se propague. Vou colocar aqui uma ilustração do CECIERJ, 2005 para ajudar na compreensão:

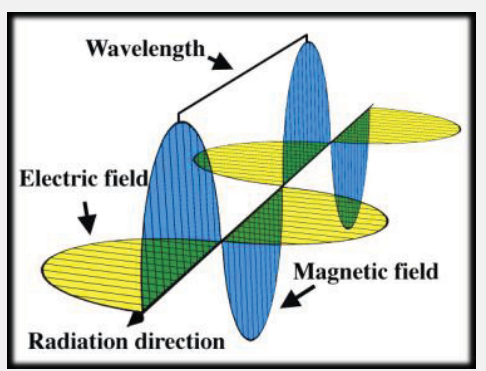

\section{Enviado em 03/11/2011 as 14:01 pm}

Olá A8, antes de pensar nas aplicações da radiação eletromagnética, vamos nos organizar... e primeiro tentar compreender o que é radiação eletromagnética?

\section{Enviado em 04/11/2011 as 4:53 pm}

Andei pesquisando num material do site que nos indicou e os autores afirmam que a luz VISÍVEL AOS OLHOS humanos é um tipo de radiação eletromagnética. Se existe uma Luz visível, aos nossos olhos, supõe-se que existe luz invisível, aos nossos olhos. 


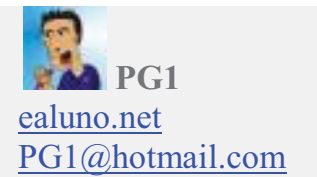

A3

A3@hotmail.com
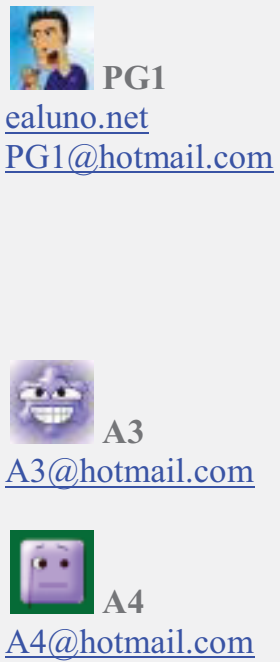

A4@,hotmail.com

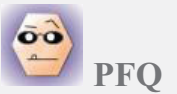

PFQ@gmail.com

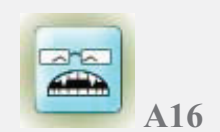

10. Enviado em 05/11/2011 as 7:53 pm

É isso aí meninos, vamos nos concentrar na compreensão deste conceito. A1 e A2, gostaria de lhes sugerir que retornem ao espectro eletromagnético lhes apresentado no OVA e procurem localizar a faixa da luz visível. Então lhes convido a refletir sobre a principal diferença entre os tipos de radiação.

\section{Enviado em 06/11/2011 as 4:38 pm}

Sobre a radiação eletromagnética, entendi que é mais ou menos um transporte da energia que é feito pela interação entre os campos elétrico e magnético.

A onda emitida pelo rádio é radiação eletromagnética?

\section{Enviado em 07/11/2011 as 5:40 pm}

Vamos lá A3, deixa-me tentar explicitar melhor a ideia: Não é mais ou menos um transporte de energia, e sim o próprio transporte de energia, mas que bom que você está participando da discussão, e, quanto a sua pergunta sobre as ondas de rádio, gostaria de estender a você o convite que fiz anteriormente a A1 e A2 sobre dar uma olhada no espectro eletromagnético...

\section{Enviado em 08/11/2011 as 13:20 pm}

Acho que o que faz as ondas diferentes é a frequência ou o comprimento de onda.

\section{Enviado em 09/11/2011 as 11:43 pm}

Retornei ao OVA e fui ao espectro eletromagnético, então pude concluir que existem diversos tipos de radiação eletromagnética, entre elas estão:

as de alta frequência - raios gama, raios-x e ultra-violeta e as de baixa frequência - luz visível, infravermelho, microondas, ondas de rádio e energia de corrente alternada.

\section{Enviado em 09/11/2011 as 15:25 pm}

É isso ai A4, porém gostaria de te perguntar se conseguiu aprender algo sobre a natureza das micro-ondas nesta atividade.

\section{Enviado em 10/11/2011 as 14:21 pm}

Olá PFQ, consultando o OVA acho que as micro-ondas são ferramenta básica para o funcionamento dos fornos em 

A16@hotmail.com questão. Essas são emitidas por magnetrons e moléculas polarizadas tal como água presentes no alimento são excita- das por esta radiação cozinhando os alimentos.

\section{Enviado em 10/11/2011 as 14:37 pm}

Os alimentos são cozidos porque algumas moléculas contidas nele vibram e a água é a principal delas. A frequência de micro-ondas corresponde a uma frequência de oscilação natural da molécula de água.

\section{Enviado em 10/11/2011 as 14:37 pm}

PFQ, não sei se alguém já respondeu, mas como funciona a válvula de megaton (eu acho que é isso)?

A18@hotmail.com

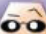

PFQ

PFQ@gmail.com

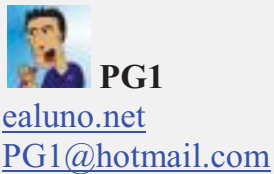

PG1@hotmail.com

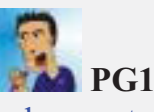

ealuno.net

\section{Enviado em 10/11/2011 as 14:37 pm}

O tubo de magnetron é responsável pela geração de ondas eletromagnéticas, na faixa de micro-ondas, que são refletidas pelas paredes metálicas internas do forno.

\section{Enviado em 10/11/2011 as 13:34 pm}

Olá meninos gostaria de, por ora, resumir algumas coisas de nossa conversa: as ondas eletromagnéticas são campos eletromagnéticos propagantes como A1, A2 e A3 falaram. Os campos elétrico e magnético oscilam em direções perpendiculares entre si e perpendiculares à direção de propagação da onda, como A2 nos disse. Também que todas as ondas são de natureza eletromagnética (como disse A1), têm mesma velocidade no vácuo (velocidade da luz como nos disse A2) e transportam energia como nos disseram A1 e A3. Ainda, diferem entre si pelo comprimento de onda e, portanto, pela frequência, como nos disseram A1, A3 e A4, o que significa serem diferentes as fontes que lhes deram origem. $\mathrm{O}$ espectro eletromagnético, apresentado no OVA, não tem limites superior e inferior definidos, somente intervalos de frequência.

E, por fim, luz é definida como a radiação que pode ser percebida pelos olhos, tal como A2 e A5 falaram, assim o espectro apresenta uma região visível.

\section{Enviado em 10/11/2011 as 15:23 pm} ram durante as discussões, sobre a radiação eletromagnética, podemos dizer que realmente algumas são nocivas aos
Pessoal, apenas para esclarecer algumas dúvidas que surgi- 
PG1@hotmail.com seres vivos em geral, mas isso dependerá de sua frequência, e mais, geralmente as ditas de alta frequência são mais nocivas...

Apenas exemplificando, as ondas de rádio e TV são eletromagnéticas, porém não causam danos a nossa saúde.

As micro-ondas até podem ser nocivas, porém o aparelho de micro-ondas comumente comercializado, conta com sistemas de segurança que reduzem em quase $100 \%$ os riscos, por meio de blindagens.

É necessário ressaltar que os testes com frutas e similares podem até indicar um vazamento, mas não são confiáveis a ponto de causar grande preocupação, desse modo, caso haja suspeita de vazamento, encaminhe o aparelho à assistência técnica que fará os devidos testes.

Este extrato foi escolhido por dois motivos: primeiro por ele apresentar uma trivialidade "aparente" e segundo porque evidencia um trabalho com linguagem escrita. Porém, cabe aqui um alerta: se por um lado a estrutura não hierarquizada e o potencial para encorajar a aprendizagem são características da internet que justificam o desenvolvimento de atividades de ensino, por outro a dificuldade para planejar atividades podem inibir a integração da internet nas práticas de sala de aula de física.

A utilização desta atividade (OVA) como estratégia para o ensino de física se constituiu pela utilização da linguagem escrita por exigir trabalho arbitrário com os significados das palavras e dos conceitos aprendidos e o seu desdobramento em uma determinada sequência: os alunos precisaram usar a linguagem escrita e esta precisou transferir a linguagem interior para o exterior. Cabe ressaltar que, segundo Vygotski (2001) a linguagem interior:

é uma linguagem etnográfica reduzida e abreviada no máximo grau. A escrita é desenvolvida no grau máximo... Trata-se de uma linguagem orientada no sentido de propiciar o máximo de inteligibilidade ao outro (VYGOTSKI, 2001, p. 316-317).

O turno 1 se caracteriza como um rito de abertura da rotina escolar em que PG1 convoca a participação dos alunos e retoma o tópico anterior trabalhado em ambiente presencial. Na produção desse turno está implicada a continuidade de um trabalho anterior partilhado pelo mesmo grupo de sujeitos, ou seja, a história desses sujeitos está implicada na palavra escrita. PG1 inclui/institui os aprendizes em lugar de protagonistas da atividade e não de meros espectadores “... nossa dis- 
cussão depende única e exclusivamente de sua participação". A partir desse lugar, ou seja, da voz de PG1 todos são atores da ação: professores e alunos.

Já no turno 2, PG1 situa os aprendizes e estabelece a atividade que será desenvolvida, também procura coordenar as ações em uma atitude assimétrica, própria de quem está mediando a relação entre aprendiz e conhecimento científico. PG1 ocupa um lugar social de interlocução, de "autoridade", e usa a ferramenta cultural para isso.

Uma vez aberto o espaço para negociação, os aprendizes começam a participar de diversas maneiras:

a) manifestando sua compreensão, como no exemplo dos turnos 3, 9 el4;

b) concordando com outra voz, como no exemplo do turno 5,

c) acrescentando nuances a essa compreensão, como no exemplo do turno 5.

E por diferentes motivos:

a) ocupar lugares, como no exemplo do turno 9;

b) responder a PG1, como no exemplo dos turnos 14 e 16;

c) em movimentos de atenção, como no exemplo do turno 11;

d) elou dispersão, como no exemplo dos turnos 4 e 6.

Ainda no turno 2, PG1 marca o contexto da atividade: "em nosso discurso" - refere-se aos conhecimentos de senso comum que utilizamos rotineiramente, pressupondo que os aprendizes também o localizem e saibam do que ele está falando, "define" o que são raios eletromagnéticos e assume, assim, a posição de participante também da atividade, não deixando de ocupar o lugar de professor. Ele ainda destaca a pergunta: $O$ que é radiação eletromagnética?

É essa pergunta que acaba sendo a chave da análise do extrato, pois é típica do discurso pedagógico (onde o professor faz a pergunta já sabendo a resposta). Assim, na tentativa de respondê-la, os professores a enunciam de diferentes maneiras para evidenciar nuances diferentes sobre o conhecimento científico em questão, tal como exemplificado em:

a) turno 7 "... gostaria de falar um pouco sobre a relação entre os campos magnético e elétrico".

b) turno 10 "... retornem ao espectro eletromagnético que foi lhes apresentado no OVA e procurem localizar a faixa da luz visivel. Então, convido-lhes a refletir sobre a principal diferença...".

c) turno 12 "... Não é mais ou menos transporte de energia e sim o próprio transporte de energia". 
Os professores (PG1 e PFQ), quando fazem a pergunta, já têm implícitas imagens que fazem de seus aprendizes, do conhecimento que têm, da maneira como falam e de como as respostas que produzirão diferem do conhecimento científico. Apesar de uma pergunta feita no contexto da aula de física que pressupõe uma resposta também desse contexto, do conhecimento de física, ou seja, definições em termos conceituais, essa pergunta feita em ambiente virtual não parece conter a expectativa ou a cobrança de um modo escolar de apresentar o conhecimento. No entanto, importa esclarecer que PG1, ainda que insira a pergunta como reguladora de funções ou ainda como controladora de significados em ambiente virtual, onde se diluem tempo e espaço, abre espaço para que a pergunta surja como possibilidade de descontrole do sentido.

PG1 e PFQ procuram não responder a cada aprendiz individualmente, mas, ao enunciarem, eles:

1) mantêm o foco no tópico - turnos 8 e 10 ;

2) respondem de certo modo - turnos 7 e 12;

3) usam recurso disciplinar chamando para o cerne da discussão - turnos 20 e 21;

4) suscitam outras possiveis respostas - turno 12.

Esses resultados nos permitem caracterizar o movimento discursivo de encontro e alternância de vozes. Os aprendizes demonstram compreender os múltiplos sentidos da pergunta (turnos $5,13,16$ ), porém também demonstram não ter familiaridade com o conceito em questão (turno 18 - "megaton"). Neste ponto, instaura-se um momento de negociação: entram em jogo as histórias de vida dos sujeitos, suas experiências e seus conhecimentos prévios sobre a temática.

No processo de repetição/explicitação da enunciação - radiação eletromagnética -, vemos surgirem várias contribuições e, nesse movimento de incorporação/apropriação da palavra, podemos caracterizar como empréstimo a voz do outro. O que entra em jogo aqui é a interlocução: enquanto respondem à pergunta de PG1 e PFQ, os alunos tecem as respostas pela enunciação dos outros alunos e também de PG1 e PFQ, ascendendo do conhecimento prévio ao conhecimento científico; realizam, assim, um trabalho pelo significado do conceito convidando e convocando para a negociação, de onde emergem enunciados que contemplam aspectos sobre a natureza da radiação eletromagnética que são destacados no diálogo por PG1 no turno 21:

a) São campos eletromagnéticos propagantes, turnos 3, 5 el1;

b) os campos elétrico e magnético oscilam em direções perpendiculares entre si e perpendiculares à direção de propagação da onda, turno 5; 
c) são descritas por comportamento ondulatório, turno 3;

d) viajam à mesma velocidade (velocidade da luz), turno 5;

e) transportam energia, turnos 3, 5 e 11;

f) diferem entre si pelo comprimento de onda e, portanto, pela frequência, turnos 3, 13 e 14;

g) é classificada como luz - a radiação eletromagnética -, que pode ser percebida pelos olhos, turnos 5 e 13.

Por sua vez, PG1 e PFQ controlam os significados (turnos 8 e 12) e, em condições concretas, instauram o diálogo. Porém, não controlam o sentido (turnos 4 e 6$)$.

No movimento de negociação, PG1 e PFQ motivam seus alunos a socializarem suas ideias e envolvem a atenção destes de modo que não dispersem (turnos 8 e 12); PG1 e PFQ valorizam as participações, comemoram as conquistas (turnos 10 e 15) e não permitem a finalização do diálogo (turno 7), isto é, incorporam e/ou organizam as vozes dos alunos. Atuam, dessa forma, como mediadores entre os alunos e o conhecimento científico, não reproduzindo mecanismos de reprodução de conhecimento, mas orientando no desenvolvimento de habilidades intelectuais de seus alunos. Adicionalmente, observou-se o envolvimento da capacidade reflexiva dos alunos através da promoção de diálogos entre os pares. Também foi observado que essa estratégia propiciou uma contribuição para o significado da Ciência e da Tecnologia e de suas relações com a Sociedade (turno 21).

Outros aspectos mereceriam considerações, mas nosso objetivo primeiro foi evidenciar modos de interação/atividade que caracterizassem a mediação pela palavra e pelo outro. Nesse sentido, nossos resultados mostram que, nesta experiência de aula de física em ambiente virtual, houve convocação explicita à participação, à interlocução e à dialogia, o que indica uma prática pedagógica/discursiva mediada.

\section{Considerações finais}

Anteriormente aos computadores, explorar e construir as representações do conhecimento científico exigia grande capacidade de abstração. Exemplo disso seria representar a existência atômica, que exigia utilizar e, portanto, compreender a equação de função de onda. Porém, hoje, o recurso computacional confere contornos mais concretos para utilizar essa equação e aplicar seu significado em contexto específico de exploração dos parâmetros da função. Nesse sentido, nossos resultados apontam que a configuração do Portal Ealuno the confere utilidade na 
ação mediada, e essa utilidade está no poder de interatividade e no acesso a ambientes virtuais, permitindo oferecer aos usuários interação e motivação para o processo de ensino-aprendizagem.

Esta investigação permite considerar que o Portal Ealuno é veículo de comunicação que pode permitir acesso a conteúdos específicos do domínio do conhecimento científico, uma vez que disponibiliza conteúdos confiáveis e consensuais entre a comunidade científica. Há que se considerar ainda que o acesso e a manipulação de informações podem ser feitos de forma rápida e sistemática diluindo espaço e tempo em prol da virtualidade.

Dessa forma, a utilização de ambiente virtual em sala de aula de física conferiu ao professor a possibilidade de se apropriar dessa tecnologia integrando-a ao ambiente de ensino-aprendizagem usual produzindo um ensino de física mais dinâmico e mais próximo das constantes transformações que a sociedade tem vivenciado, contribuindo para diminuir a distância que separa a educação básica das ferramentas modernas de produção de difusão do conhecimento. Quando o professor (agente) fez uso da ferramenta cultural (Ealuno - ambiente virtual) para executar sua ação, este demonstrou noções de domínio dessa ferramenta e, assim, potencializou a sua ação mediada.

Todavia, a ação mediada pode ser determinada pela tensão entre ferramenta cultural e mediador e, neste caso, quando essa comunidade escolar domina e se apropria de TIC's, reconhece que tanto elaboração de significados como apropriação de ferramentas culturais são processos acoplados que podem ser explicados na perspectiva da ação mediada.

Finalmente, cabe considerar que cada vez mais seremos envolvidos pelas TIC's e, assim, importa ter delas o devido controle epistemológico e democrático sem resistências desnecessárias ou ultrapassadas e, sobretudo, sem entusiasmos acríticos. É necessário saber que muitas de suas promessas são vãs, mas muitas são reais e cruciais para o futuro da educação. Acrescentamos que a escola deve integrar as TIC's, visto que elas já estão presentes e influentes em todas as esferas da vida social, cabendo à escola atuar também no sentido de compensar as desigualdades sociais e regionais que o acesso desigual ao ensino de qualidade está gerando.

\section{Agradecimentos}

À Fundação de Amparo à Pesquisa do Estado de Goiás (FAPEG) e ao Conselho Nacional de Desenvolvimento Científico e Tecnológico (CNPQ) pelos fomentos concedidos ao desenvolvimento desta pesquisa. 


\section{Referências}

ALEXANDER, B. Web 2.0: A new wave of innovation for teaching and learning? Educause Review, v. 41, n. 2, p. 32-44, 2006. Disponível em: $<$ http://www.educause.edu/EDUCAUSE+Review/EDUCAUSEReviewMagazineV olume41/Web20ANewWaveofInnovationforTe/158042> Acesso em: 26 jan. 2011.

BARBOZA, A. C. R. N. et al. Aquecimento em forno de microondas/desenvolvimento de alguns conceitos fundamentais. Química Nova, v. 24, n. 6, p. 901-904, 2001.

BARTOLOMÉ, A. R. Nuevas tecnologias en el aula. Barcelona: Gaò, 1999.

BARTOlOMÉ, A. R. Comunicación, educación y tecnologia. Actas... do III Sopcom, VI Lusocome II Ibérico, n. 4, p. 299-309, 2005. Disponível em:

$<$ http://www.bocc.uff.br/pag/bartolome-antonio-comunicacion-educaciontecnologia.pdf>. Acesso em: 20 jan. 2011.

BEHAR, P. et al. Modelos Pedagógicos em Educação a Distância. Porto Alegre: Ed. Artmed, 2009.

BENITE, A. M. C; BENITE, C. R. M. O computador no ensino de química: Impressões versus Realidade. Em Foco as Escolas Públicas da Baixada Fluminense. Ensaio - Pesquisa em Educação em Ciências, Belo Horizonte, v. 10, n. 2, p. 303-319, 2008.

BENITE, A. M. C.; BENITE, C. R. M.; SILVA-FILHO, S. M. Cibercultura em Ensino de Química: Elaboração de um Objeto Virtual de Aprendizagempara o Ensino de Modelos Atômicos. Química Nova na Escola, São Paulo, v. 33, n. 2, p. 71-76, mai. 2011.

BRANDÃO, C. R. (Org.). Pesquisa Participante. São Paulo: Brasiliense, 1984.

D’AMBRÓSIO, U. Educação Matemática. Da teoria à prática. 7. ed. Campinas: Papirus, 1996.

DEMO, P. Pesquisa participante: saber pensar e intervir juntos. Brasília: Plano, 2004.

DOWBOR, L. Tecnologias do conhecimento: os desafios da educação. Petrópolis: Ed. Vozes, 2001. 
GARCIA, F. M. Tecnologia e educação: relações históricas, locais e mundializadas. Revista Novas Tecnologias na Educação, Porto Alegre, v. 3 n. 1, mai. 2005.

GARFINKEL, H. Studies in ethnomethodology. EnglewoodCliffs, N. J.: Prentice-Hall, c1967.

HERITAGE, J. Etnometodologia. In: GIDDENS, A.; TURNER, J. Teoria social hoje. São Paulo: Ed. UNESP, 1999.

KENSKI, V. M. Educação e Tecnologias: o novo ritmo da informação. Campinas: Papirus, 2007.

LÉVY, P. As tecnologias da inteligência. Rio de Janeiro: Ed. 34, 1993.

LINDLEY, R. Economias baseadas no conhecimento - o debate europeu sobre o emprego num novo contexto. In: RODRIGUES, M. J. (Org.). Para uma Europa da Inovação e do conhecimento - Emprego, reformas econômicas e coesão social. Oeiras: Celta, 2000. p. 33-78.

MACHADO, J. A compreensão de licenciados em física sobre modelos e modelização. In: MORTIMER, E. F. (Org.). ENCONTRO NACIONAL DE PESQUISA EM EDUCAÇÃO EM CIÊNCIAS, 7, 2009, Florianópolis. Anais... Florianópolis, ABRAPEC, v. 1, 2009. p.1-12.

MARCUSCHI, L. A. Análise da Conversação. São Paulo: Ed Ática, 2007.

MARTINS, C. A.; SANTANA, J. R. Cultura imagética e suas implicações filosóficas na formação de professores. In: SIMPÓSIO NACIONAL DA ASSOCIAÇÃO BRASILEIRA DE PESQUISADORES EM CIBERCULTURA, 3, São Paulo, 2009. Anais... São Paulo, ABCiber, 2009.

O'REILLY, T. What is web 2.0.design patterns and business models for the next generation of software, 2005. Disponível em:

$<\mathrm{http} / /$ www.oreillynet.com/pub/a/oreilly/tim/news/2005/09/30/what-is-web-

20.html>. Acesso em: 15 jan. 2011.

POSTMAN, N. Tecnopólio: a rendição da cultura à tecnologia. São Paulo: Nobel, 1994.

POZO, J. I. Aprendizes e mestres: a nova cultura da aprendizagem. Porto Alegre: Artmed, 2002. 
SMOLKA, A. L. B. A prática discursiva na sala de aula: Uma perspectiva teórica e um esboço de análise. Caderno Cedes, v. 24, p. 51-65, 1991.

VEIT, E. A.; TEODORO, V. D. Modelagem no ensino/aprendizagem de física e os novos parâmetros curriculares nacionais para o ensino médio. Revista Brasileira de Ensino de Física, v. 24, n. 2, p. 87-96, 2002.

VYGOTSKI, L. S. A construção do pensamento e da linguagem. São Paulo: Martins Fontes, 2001 